\title{
Sistem PENDUKUng KePUTUSAN DENGAN MENERAPKAN METODE ElECTRE DALAM MENENTUKAN RANGKING KINERJA KARYAWAN (STUDI KASUS: INSTANSI XYZ)
}

\author{
Dimas Wahyu Wibowo ${ }^{1}$, Rawansyah ${ }^{2}$, Rizky Ardiansyah ${ }^{3}$ \\ 1,2) Teknik Informatika, Politeknik Negeri malang \\ 1)dimas.w@polinema.ac.id, ${ }^{2)}$ rawansyah@polinema.ac.id, ${ }^{3)}$ rizkyardiansyah@polinema.ac.id
}

\begin{abstract}
Abstrak - Pada sebuah perusahan tentunya mempunyai penilaian terhadap karyawan yang berkerja. Penilaian Kinerja ini digunakan sebagai bahan pertimbangan perusahan dalam mengangkat karyawan untuk menduduki jabatan-jabatan strategis atau untuk mendapatkan tambahan tunjangan. Untuk penilaian kinerja karyawan ini dilakukan oleh manajer atau asisten manajer pada tiap-tiap devisi. Permasalahan muncul pada subjektifitas dalam memberikan penilaian kepada karyawan karena yang dinilai adalah subjektifitas masing masing karyawan. Sehingga penilaian yang diberikan masih tidak pasti. Adanya ketidaktepatan dalam memberikan nilai kepada karyawan berdampak pada hasil keputusan yang diberikan kurang optimal.Sehingga diperlukan sistem pendukung keputusan yang dapat membantu perusahaan dalam mengambil keputusan. Dengan menggunakan Sistem Pendukung Keputusan menggunakan ELECTRE diharapkan dapat mempermudahkan perusahaan dalam menentukan rangking kinerja karyawan.
\end{abstract}

Kata kunci : Kinerja karyawan, Sistem Pendukung Keputusan, Electre

\section{PENDAHULUAN}

$\mathrm{P}$ ada sebuah perusahan tentunya mempunyai penilaian terhadap karyawan yang berkerja. Penilaian Kinerja ini digunakan sebagai bahan pertimbangan perusahan dalam mengangkat karyawan untuk menduduki jabatan-jabatan strategis atau untuk mendapatkan tambahan tunjangan. Untuk penilaian kinerja karyawan ini dilakukan oleh manajer atau asisten manajer pada tiap-tiap devisi. Permasalahan muncul pada subjektifitas dalam memberikan penilaian kepada karyawan karena yang dinilai adalah subjektifitas masing masing karyawan. Sehingga penilaian yang diberikan masih tidak pasti. Adanya ketidaktepatan dalam memberikan nilai kepada karyawan berdampak pada hasil keputusan yang diberikan kurang optimal.

Berdasarkan pemaparan masalah diatas, maka diusulkan sebuah ide untuk membuat sistem pendukung keputusan evaluasi kinerja karyawan menggunakan metode ELimination and Choice Expressing Reality (ELECTRE). Hal ini dimaksudkan untuk membantu manajer dan asisten manajer dalam memberikan nilai secara objektif berdasarkan tingkat kepentingan yang berbedabeda pada setiap kriteria yang ada, berdasarkan departmen yang dibawahi manajer dan asisten manajer. Pada sistem ini dilakukan perhitungan terhadap seluruh kriteria, kemudian menampilkan hasil rangking dari yang nilainya tertinggi hingga terendah, sehingga dapat memudahkan pihak koordinator dalam melakukan evaluasi kinerja karyawan dan dapat digunakan sebagai bahan acuan perusahaan untuk keputusan kontrak karyawan atau hanya sekedar pemberian hadiah terhadap karyawan yang berprestasi.

\section{Tinjauan Pustaka}

\section{A. Sistem Pendukung Keputusan (SPK)}

Menurut Turban Sistem Pendukung Keputusan (SPK) atau Decision Support System (DSS) adalah sebuah sistem yang dapat memecahkan masalah dengan kondisi semi terstruktur dan tak 
terstruktur (Turban, 2005:1). SPK dapat membantu memberikan penilaian terhadap alternatif dalam pengambilan keputusan. Proses pengambilan keputusan terdiri dari tiga fase proses, yaitu:

Fase intelligence atau studi kelayakan, dalam tahap ini dilakukan proses identifikasi masalah Fase design atau perancangan, dalam tahap ini memformulasikan model yang akan digunakan dan menentukan kriteria. Fase choice atau pemilihan, dalam tahap ini didapatkan keluaran berupa solusi permasalahan. Sistem Pendukung Keputusan terdiri dari tiga komponen utama yaitu: Subsistem data, merupakan komponen penyedia data yang diperlukan oleh sistem. Subsistem model, merupakan komponen yang mengubah data menjadi sebuah informasi yang berguna bagi sistem. Antarmuka pengguna, komponen ini berfungsi sebagai sarana interaksi antara user dengan sistem.

\section{B. Elimination and Choise Expressing Reality (ELECTRE)}

Metode electre digunakan pada kondisi dimana alternatif yang kurang sesuai dengan kriteria dieliminasi, dan alternatif yang sesuai dapat dihasilkan. Dengan kata lain, electre digunakan untuk kasus-kasus dengan banyak alternatif namun hanya sedikit kriteria yang dilibatkan.

Langkah-langkah yang dilakukan dalam penyelesaian masalah menggunakan metode ELECTRE adalah sebagai berikut:

1. Normalisasi matrik keputusan.

ELECTRE dimulai dari membentuk tabel rating kecocokan, yaitu perbandingan berpasangan setiap alternatif pada setiap kriteria $\left(X_{i j}\right)$. Nilai ini harus dinormalisasikan ke dalam suatu skala yang dapat diperbandingkan $\left(r_{i j}\right)$, sehingga dapat dituliskan pada persamaan 1 :

$$
r_{i j}=\frac{X_{i j}}{\sqrt{\sum_{i=1}^{m} X^{2} i j}}
$$

Ket : $r=$ Bilangan ternormalisasi

$\mathrm{X}=$ kriteria, $\mathrm{i}=1,2,3, \mathrm{~m}, \mathrm{j}=1,2,3, \mathrm{n}$

\section{Menentukan Tabel V}

Selanjutnya pengambilan keputusan harus memberikan faktor kepentingan (bobot) pada setiap kriteria yang mengekspresikan kepentingan relatifnya (Wi), sehingga dapat dituliskan pada persamaan:

$$
\begin{aligned}
& \mathrm{W}=(\mathrm{w} 1, \mathrm{w} 2, \ldots \ldots \ldots \ldots \mathrm{wn}) \\
& \text { Dengan } \sum_{i=1}^{n} w_{i}=1
\end{aligned}
$$

Bobot ini selanjutnya dikalikan dengan matriks perbandingan berpasangan membentuk metrik $\mathrm{V}$, sehingga dapat dituliskan pada persamaan:

$$
V_{i j}=W_{j} X_{i j}
$$

\section{Menentukan Corcondance dan Discordance Index}

Pembentukan corcondance index dan discordance index untuk setiap pasangan alternatif dilakukan melalui taksiran terhadap relasi perangkingan. Untuk setiap pasangan alternatif $A_{k}$ dan $\mathrm{A}_{1}\left(\mathrm{k}, \mathrm{l}=1,2, \ldots, \mathrm{m}\right.$ dan $\left.\mathrm{k}^{1} \mathrm{l}\right)$, matriks keputusan untuk kriteria $\mathrm{j}$, terbagi menjadi 2 himpunan bagian. Pertama, himpunan corcondance index $\left\{\mathrm{C}_{\mathrm{kl}}\right\}$ menunjukan penjumlahan bobot-bobot kriteria yang mana alternatif $A_{k}$ lebih baik daripada alternatif $A_{1}$, sehingga dapat dituliskan pada persamaan 4:

$$
C_{k l}=\left(j \mid V_{k j} \geq V_{i j}\right)
$$


untuk $\mathrm{j}=1,2, \ldots \ldots, \mathrm{n}$

Kedua, himpunan corcondance index $\left\{d_{k l}\right\}$ diberikan sebagai berikut sehingga dapat dituliskan pada persamaan 5:

$D_{k l}=\left(j \mid V_{k j} \leq V_{i j}\right)$

Untuk $\mathrm{j}=1,2, \ldots \ldots, \mathrm{n}$

4. Menghitung nilai $\mathrm{C}$ dan $\mathrm{D}$ tiap alternatif

Setelah dibandingkan berdasarkan concordance dan discordance index, selanjutnya akan dihitung total nilai $\mathrm{C}$ dan $\mathrm{D}$ berdasarkan bobot preferensi yang dimilikinya. Selanjutnya perangkingan akan dilihat dari selisih nilai $\mathrm{C}$ dan $\mathrm{D}$ pada alternatf. Alternatif dengan nilai yang terbesar akan mendapat rangking paling atas.

\section{Metode Penelitian}

\section{A. Desain Perancangan Sistem}

\section{Analisa Use Case}

Analisa use case dibuat untuk menggambarkan aktivitas-aktivitas yang dilakukan dalam sistem. Model analisa use case diwakili dengan diagram use case. Diagram use case menggambarkan fungsionalitas sistem sebagai prosedur/aturan yang disepakati sistem berjalan sesuai dengan yang diinginkan. Dalam diagram use case juga digambarkan interaksi antar actor dengan sistem untuk melengkapi fungsi-fungsi sistem. Diagram use case terdiri dari actor, hubungan (relationship), dan use case. Pada setiap analisis use case akan diuraikan spesifikasi dan deskripsi analisis use case. Spesifikasi analisis use case merupakan item-item yang digunakan menjelaskan aktivitas dalam analisis use case tersebut, seperti Brief Description, Preconditions, Actor, Precondition, dan Post Condition, aliran utama dan alternatif aktivitas dari setiap analisis use case, dan seterusnya.

\section{Diagram Use Case}

Diagram Use case untuk sistem pengambilan keputusan metode ELECTRE dapat diperlihatkan dalam gambar 1

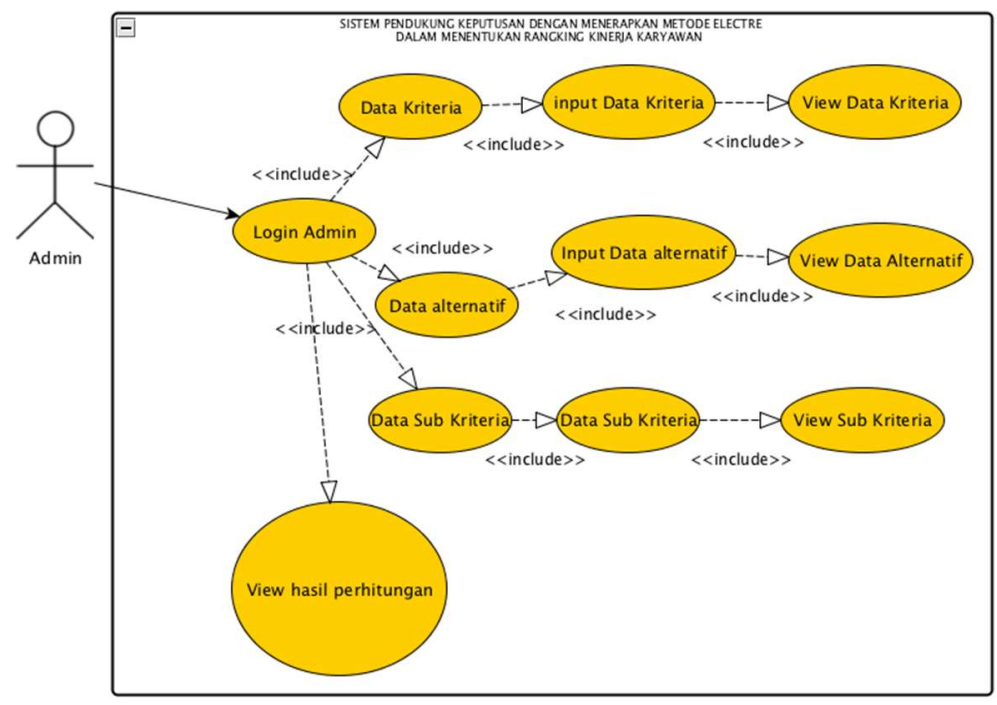

Gambar 1 Diagram Use case 


\section{Konsep Pembentukan Database}

Pembentukan database ini mempunyai lima tabel yaitu kriteria, sub kriteria, altenatif, nilai dan tabel user. Pada tabel kriteria digunakan untuk menyimpan kriteria-kriteria yang digunakan untuk perhitungan. Pada tabel sub kriteria digunakan untuk menyimpan data-data sub pada masing-masing kriteria. Pada tabel alternatif digunakan menyimpan data-data alternatif. Pada tabel nilai digunakan untuk menyimpan hasil perhitungan yang nantinya akan dirangkingkan pada sistem. Sedangkan pada tabel user digunakan untuk menyimpan username dan password dari user.

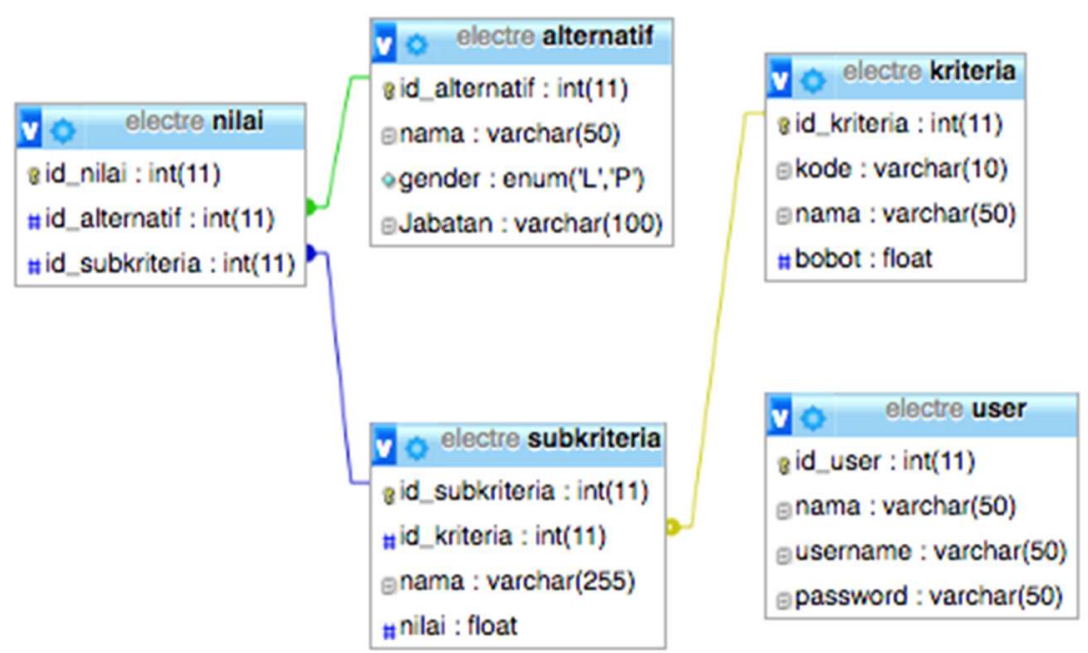

\section{Gambar 2 Struktur tabel pada database electre}

\section{Pengujian Sistem}

Pengujian sistem diperlukan untuk melihat kualitas dan kemampuan sistem dalam menerapkan metode electre. Adapun kriteria-kriteria yang digunakan untuk mendukung sistem antara lain:

1. Aspek Teknis Penilaian(K01)

- Efektifitas dan Effsiensi Kerja, Ketepatan waktu dalam menyelesaikan tugas, Kemp.mencapai target / standart perusahaan

2. Aspek Non Teknis(K02)

- Tertib Administrasi, Inisiatif, Kerjasama dan Koordinasi antar bagian

3. Aspek Kepribadian(K03)

- Perilaku, Kedisplinan, Tanggung Jawab dan loyalitas

4. Aspek Kepemimpinan(K04)

- Koordinasi anggota, Kontrol anggota, Evaluasi dan pembinaan anggota, Delegasi tanggung jawab dan wewenang, Kecepatan dan ketepatan pengambil keputusan

\section{Hasil Penelitian dan Pembahasan}

Bab ini merupakan hasil dan pembahasan sistem penerapan metode ELECTRE dalam menentukan rangking kinerja karyawan. Proses melakukan identifikasi dilakukan dengan melaksanakan penelitian dan observasi pada sistem yang sedang berjalan. Hasil penelitianpenelitian tersebut dipergunakan untuk masukan ke dalam sistem yang akan dikembangkan.

\section{A. Antar Muka Pengguna}

Antar muka pengguna digunakan untuk memudahkan user dalam melakukan operasi perhitungan. Pada antar muka ini akan dijabarkan di beberapa bagian yang akan digunakan oleh user. 


\section{Halaman Kriteria}

Pada halaman kriteria ini user memasukkan kriteria yang akan digunakan beserta bobot masing-masing kriteria

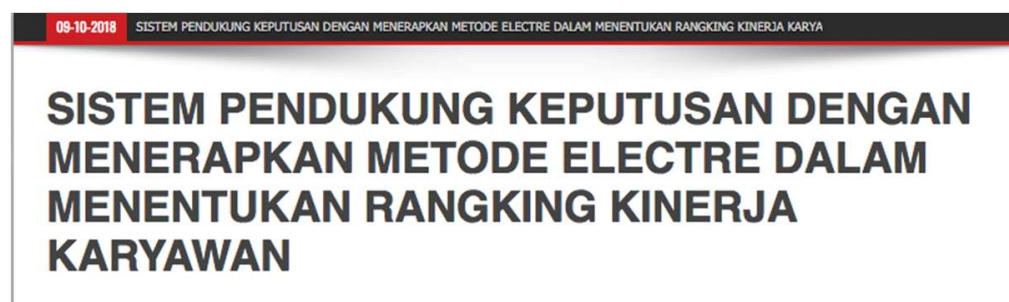

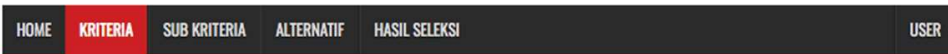

Data Kriteria

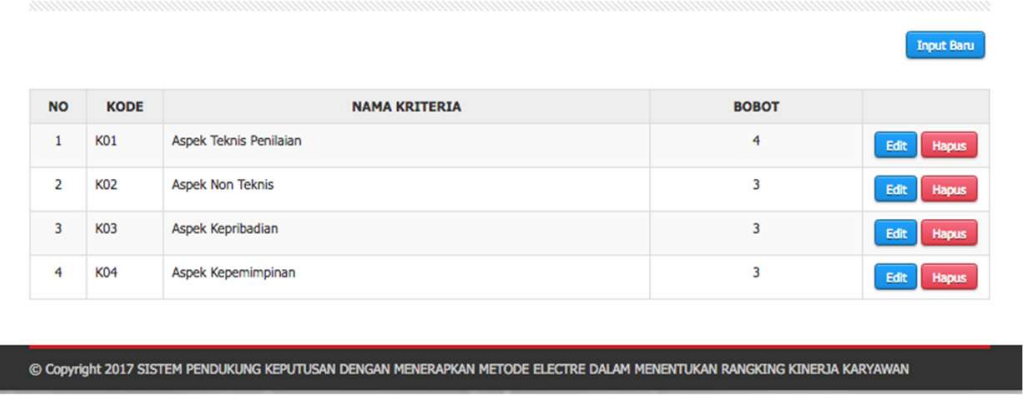

Gambar 3 Tampilan inputan Kriteria

\section{Halaman Sub Kriteria}

Halaman ini digunakan untuk menambahkan subkriteria pada masing-masing kriteria yang sudah dibuat dihalaman kriteria.

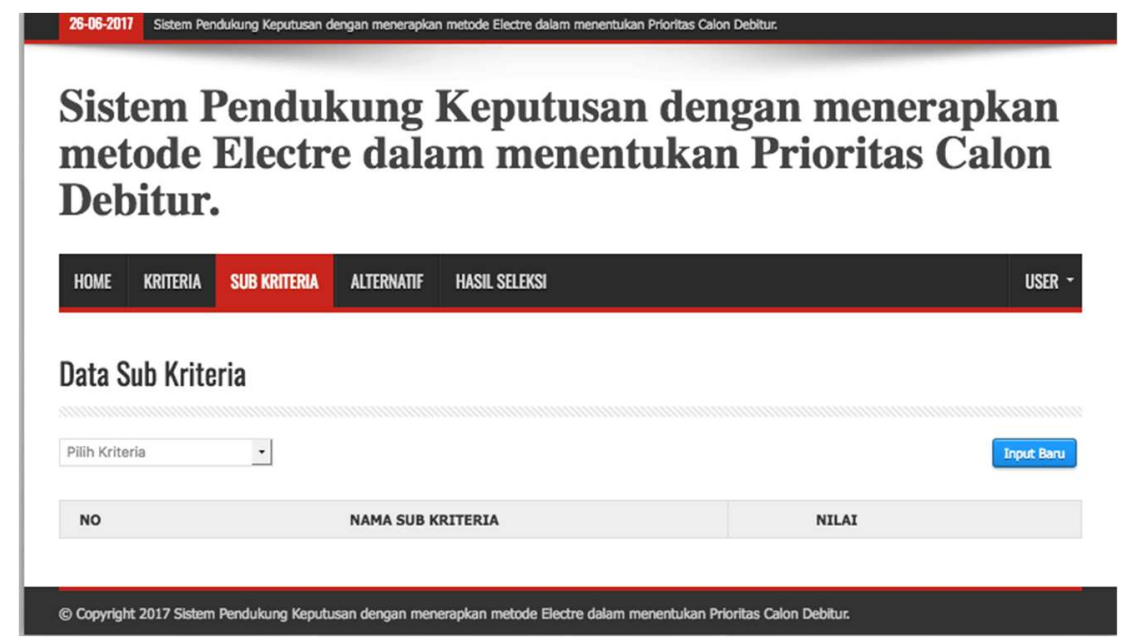

Gambar 4 Tampilan inputan Sub Kriteria

\section{B. Pengujian}

Pada halaman hasil seleksi user dapat melihat hasil perhitungan dari metode electre berdasarakan data-data alternatif yang telah diinputkan oleh user pada halaman alternatif. Pada halaman hasil selesi user dapat melihat beberapa informasi dan hasil perhitungan antara lain Tabel Rating kecocokan adalah tabel nilai berdasarkan nilai dari masing-masing kriteria yang telah diinputkan oleh user, Bobot kriteria adalah bobot yang telah ditentukan oleh user, matrik ternomalisasi adalah hasil pembagian antara salah satu nilai kriteria dengan akar kuadrat dari total 
kriteria tersebut, Tabel $\mathrm{V}$ adalah hasil perkalian dari bobot salah satu kriteria dengan matrix ternomalisasi sehingga menghasilkan tabel hasil perangkingan yang merupakan hasil akhir dari perhitungan.

\begin{tabular}{|c|c|c|c|c|c|}
\hline NO & NAMA PEMOHON & K01 & K02 & K03 & KO4 \\
\hline 1 & AHMAD FAUZAN & 2 & 2 & 2 & 3 \\
\hline 2 & AHMAD HARIYANTO & 3 & 2 & 3 & 2 \\
\hline 3 & ALFIYAN MUHTAR WAHDAH & 2 & 2 & 2 & 2 \\
\hline 4 & EDI SUKAMTO & 2 & 2 & 2 & 3 \\
\hline 5 & FAIDATUL ROHMAN ARISKI & 3 & 3 & 3 & 3 \\
\hline 6 & INDRA ADI SUCIPTO & 2 & 3 & 2 & 2 \\
\hline 7 & LUKMAN HAKIM & 2 & 3 & 3 & 3 \\
\hline 8 & M. HOLILI & 2 & 3 & 2 & 2 \\
\hline 9 & MOCH SUWARDI & 2 & 2 & 2 & 2 \\
\hline 10 & MOH EKO WAHYUDI & 2 & 2 & 3 & 2 \\
\hline 11 & MOH TAUFIK HIDAYAT & 2 & 3 & 2 & 3 \\
\hline 12 & MUHAMMAD IRVAN DULKIFLI & 2 & 2 & 2 & 2 \\
\hline 13 & NANANG SOETJAHJO ADI & 2 & 2 & 2 & 2 \\
\hline 14 & PRIYANTO & 2 & 2 & 2 & 3 \\
\hline 15 & RAMA HIDAYAT & 2 & 2 & 2 & 2 \\
\hline 16 & RLAN PUJI RAHMAN & 3 & 2 & 2 & 2 \\
\hline 17 & ROFIK & 2 & 2 & 2 & 2 \\
\hline 18 & SAIFUL RIJAL & 2 & 2 & 3 & 3 \\
\hline 19 & SEPTIAN PURNOMO & 2 & 3 & 2 & 2 \\
\hline 20 & TONI ANORIAWAN & 2 & 2 & 2 & 2 \\
\hline
\end{tabular}

\section{Gambar 5 Halaman Seleksi ( Tabel Rating Kecocokan)}

Bobot kriteria adalah bobot yang telah ditentukan oleh user

BOBOT KRITERIA

\begin{tabular}{|c|c|c|c|}
\hline K01 & K02 & K03 & K04 \\
\hline 4 & 3 & 3 & 3 \\
\hline
\end{tabular}

NILAI $X$

\begin{tabular}{|c|c|c|c|}
\hline $\mathbf{X} 1$ & $\mathbf{X}$ & $\mathbf{X}$ & $\mathbf{X}$ \\
\hline 9.746794 & 10.488088 & 10.246951 & 10.723805 \\
\hline
\end{tabular}

\section{Gambar 6 Halaman Seleksi (Bobot Kriteria dan Nilai X)}

matrik ternomalisasi adalah hasil pembagian antara salah satu nilai kriteria dengan akar kuadrat dari total kriteria tersebut 
MATRIK TERNORMALISASI

\begin{tabular}{|c|c|c|c|c|c|}
\hline NO & NAMA PEMOHON & K01 & K02 & K03 & KO4 \\
\hline 1 & AHMAD FAUZAN & 0.205196 & 0.190693 & 0.19518 & 0.279751 \\
\hline 2 & AHMAD HARIYANTO & 0.307794 & 0.190693 & 0.29277 & 0.186501 \\
\hline 3 & ALFIYAN MUHTAR WAHDAH & 0.205196 & 0.190693 & 0.19518 & 0.186501 \\
\hline 4 & EDI SUKAMTO & 0.205196 & 0.190693 & 0.19518 & 0.279751 \\
\hline 5 & FAIDATUL ROHMAN ARISKI & 0.307794 & 0.286039 & 0.29277 & 0.279751 \\
\hline 6 & INDRA ADI SUCIPTO & 0.205196 & 0.286039 & 0.19518 & 0.186501 \\
\hline 7 & LUKMAN HAKIM & 0.205196 & 0.286039 & 0.29277 & 0.279751 \\
\hline 8 & M. HOLILI & 0.205196 & 0.286039 & 0.19518 & 0.186501 \\
\hline 9 & MOCH SUWARDI & 0.205196 & 0.190693 & 0.19518 & 0.186501 \\
\hline 10 & MOH EKO WAHYUDI & 0.205196 & 0.190693 & 0.2927 & 0.186501 \\
\hline 11 & MOH TAUFIK HIDAYAT & 0.205196 & 0.286039 & 0.19518 & 0.279751 \\
\hline 12 & MUHAMMAD IRVAN DULKIFLI & 0.205196 & 0.190693 & 0.19518 & 0.186501 \\
\hline 13 & NANANG SOETJAHJO ADI & 0.205196 & 0.190693 & 0.19518 & 0.186501 \\
\hline 14 & PRIYANTO & 0.205196 & 0.190693 & 0.19518 & 0.279751 \\
\hline 15 & RAMA HIDAYAT & 0.205196 & 0.190693 & 0.19518 & 0.186501 \\
\hline 16 & RLAN PUJI RAHMAN & 0.307794 & 0.190693 & 0.19518 & 0.186501 \\
\hline 17 & ROFIK & 0.205196 & 0.190693 & 0.19518 & 0.186501 \\
\hline 18 & SAIFUL RUAL & 0.205196 & 0.190693 & 0.29277 & 0.279751 \\
\hline 19 & SEPTIAN PURNOMO & 0.205196 & 0.286039 & 0.19518 & 0.186501 \\
\hline 20 & TONI ANDRIAWAN & 0.205196 & 0.190693 & 0.19518 & 0.186501 \\
\hline
\end{tabular}

\section{Gambar 7 Halaman Seleksi ( Matrik Ternomalisasi)}

Tabel V adalah hasil perkalian dari bobot salah satu kriteria dengan matrix ternomalisasi sehingga menghasilkan tabel hasil perangkingan yang merupakan hasil akhir dari perhitungan.

\begin{tabular}{|c|c|c|c|c|c|}
\hline NO & NAMA PEMOHON & K01 & K02 & K03 & K04 \\
\hline 1 & AHMAD FAUZAN & 0.820784 & 0.572079 & 0.58554 & 0.839253 \\
\hline 2 & AHMAD HARIYANTO & 1.231176 & 0.572079 & 0.87831 & 0.559503 \\
\hline 3 & ALFIYAN MUHTAR WAHDAH & 0.820784 & 0.572079 & 0.58554 & 0.559503 \\
\hline 4 & EDI SUKAMTO & 0.820784 & 0.572079 & 0.58554 & 0.839253 \\
\hline 5 & FAIDATUL ROHMAN ARISKI & 1.231176 & 0.858117 & 0.87831 & 0.839253 \\
\hline 6 & INORA ADI SUCIPTO & 0.820784 & 0.858117 & 0.58554 & 0.559503 \\
\hline 7 & LUKMAN HAKIM & 0.820784 & 0.858117 & 0.87831 & 0.839253 \\
\hline 8 & M. HOLII & 0.820784 & 0.858117 & 0.58554 & 0.559503 \\
\hline 9 & MOCH SUWARDI & 0.820784 & 0.572079 & 0.58554 & 0.559503 \\
\hline 10 & MOH EKO WAHYUDI & 0.820784 & 0.572079 & 0.87831 & 0.559503 \\
\hline 11 & MOH TAUFIK HIDAYAT & 0.820784 & 0.858117 & 0.58554 & 0.839253 \\
\hline 12 & MUHAMMAD IRVAN DULKIFLI & 0.820784 & 0.572079 & 0.58554 & 0.559503 \\
\hline 13 & NANANG SOETJAHJO ADI & 0.820784 & 0.572079 & 0.58554 & 0.559503 \\
\hline 14 & PRIYANTO & 0.820784 & 0.572079 & 0.58554 & 0.839253 \\
\hline 15 & RAMA HIDAYAT & 0.820784 & 0.572079 & 0.58554 & 0.559503 \\
\hline 16 & RLAN QUIT RAHMAN & 1.231176 & 0.572079 & 0.58554 & 0.559503 \\
\hline 17 & ROFIK & 0.820784 & 0.572079 & 0.58554 & 0.559503 \\
\hline 18 & SAIFUL RDAL & 0.820784 & 0.572079 & 0.87831 & 0.839253 \\
\hline 19 & SEPTIAN PURNOMO & 0.820784 & 0.858117 & 0.58554 & 0.559503 \\
\hline 20 & TONI ANDRIAWAN & 0.820784 & 0.572079 & 0.58554 & 0.559503 \\
\hline
\end{tabular}

Gambar 8 Halaman Seleksi ( Tabel V) 


\begin{tabular}{|c|c|c|c|c|c|}
\hline No & NAMA PEMOHON & CONCORDANCE & DISCORDANCE & (C-D) & RANGKING \\
\hline 1 & FAIDATUL ROHMAN ARISKI & 247 & 0 & 247 & 1 \\
\hline 2 & LUKMAN HAKIM & 235 & 12 & 223 & 2 \\
\hline 3 & MOH TAUFIK HIDAYAT & 220 & 27 & 193 & 3 \\
\hline 4 & SAIFUL RDAL & 217 & 30 & 187 & 4 \\
\hline 5 & AHMAD HARIYANTO & 208 & 39 & 169 & 5 \\
\hline 6 & PRIYANTO & 202 & 45 & 157 & 6 \\
\hline 7 & AHMAD FAUZAN & 202 & 45 & 157 & 7 \\
\hline 8 & EOI SUKAMTOO & 202 & 45 & 157 & 8 \\
\hline 9 & INDRA ADI SUCIPTO & 199 & 48 & 151 & 9 \\
\hline 10 & SEPTIAN PURNOMO & 199 & 48 & 151 & 10 \\
\hline 11 & M. HOLIUI & 199 & 48 & 151 & 11 \\
\hline 12 & MOH EXO WAHYUDI & 196 & 51 & 145 & 12 \\
\hline 13 & RIAN PUJI RAHMAN & 193 & 54 & 139 & 13 \\
\hline 14 & NANANG SOETJAHJO ADI & 181 & 66 & 115 & 14 \\
\hline 15 & TONI ANDRLAWAN & 181 & 66 & 115 & 15 \\
\hline 16 & RAMA HIDAYAT & 181 & 66 & 115 & 16 \\
\hline 17 & MUHAMMAD IRVAN DULKIFLI & 181 & 66 & 115 & 17 \\
\hline 18 & MOCH SUWARDI & 181 & 66 & 115 & 18 \\
\hline 19 & ROFIK & 181 & 66 & 115 & 19 \\
\hline 20 & ALFIYAN MUHTAR WAHDAH & 181 & 66 & 115 & 20 \\
\hline
\end{tabular}

\section{Gambar 9 Halaman Seleksi ( Hasil Perangkingan)}

\section{KESIMPULAN DAN SARAN}

\section{A. Kesimpulan}

Berdasarkan hasil analisis, perancangan, dan implementasi, telah berhasil dibangun sebuah sistem pendukung keputusan sehingga dapat ditentukan keputusan yang objektif. Keputusan (Rangking atau prioritas) yang dihasilkan dari sistem pendukung keputusan untuk menentukan perangkingan karyawan berdasarkan kinerja dengan metode electre bukanlah suatu keputusan (Rangking prioritas) yang mutlak dimana keputusan akhir tetap ditentukan sendiri oleh User. Jadi sistem pendukung keputusan merupakan suatu program bantu dalam mempertimbangkan suatu pengambilan keputusan. Sehingga penulis mengambil beberapa kesimpulan:

1. Sistem penunjang keputusan menggunakan metode electre dapat membantu menentukan layak dan tidak berdasarkan kriteria-kriteria yang telah ditentukan oleh perusahaan.

2. Sistem dapat membantu user dalam mengambil keputusan untuk menentukan rangking berdasarkan kinerja karyawan yang tepat sehingga dapat meminimalisir resiko penyalahgunaan jabatan.

\section{B. Saran}

Untuk penelitian selanjutnya dapat menggunakan metode Fuzzy AHP untuk proses perangkingan dan menambahkan beberapa kriteria-kriteria pendukung lainnya. Metode Fuzzy AHP adalah penggabungan 2 metode yang berbeda,metode Fuzzy dapat digunakan untuk proses clustering dan metode AHP dapat digunakan untuk proses klasifikasi. 


\section{Daftar Pustaka}

[1] Turban, Efraim, 2005, Sistem Pendukung Keputusan dan Sistem Cerdas, Andi, Yogyakarta.

[2] Kusrini, Konsep dan Aplikasi Sistem Pendukung Keputusan. Yogyakarta : Penerbit ANDI, 2007.

[3] Abner Adi Putra, Desi Andreswari, Boko Susilo, Sistem Pendukung Keputusan Untuk Penerima bantuan Pinjaman Samisaki Dengan Metode ELECTRE ( Studi Kasus:LKM Kelurahan Lingkar Timur Kota Bengkulu), Jurnal Rekursif, Vol 3 No 1 Maret 2015, ISSN 2303-0755

[4] Agustino, Addy Suyatno, dan Indah Fitri A, Sistem Pendukung Keputusan Pemilihan Kamera Digital single Lens Reflex Menggunakan Metode Elimination Et Choix Traduisant La Realite(ELECTRE), Jurnal Informatika Mulawarman, Vol 9 No 2 Juni 2014

[5] Fahmi Setiawan, Fatma Indriani, dan Muliadi, Implementasi Metode Electre Pada Sistem Pendukung Keputusan SNMPTN jalur Undangan, Kumpulan Jurnal Ilmu Komputer, Vol 02 No 02 September 2015, ISSN:2406-7857

[6] Subakti, I, 2002, Sistem Pendukung Keputusan, Jurusan Teknik Informatika, Fakultas Teknologi Informasi, Institut Teknologi Sepuluh November, Surabaya.

[7] Suryadi K. dan M. A Ramdhani, 1998, Sistem Pendukung Keputusan, PT. Remaja Rosdakarya, Bandung.

[8] Cahya R, Dimas WW dan Pramana YS, Sistem Pendukung Keputusan Dengan Menerapkan Metode ELECTRE dalam Menentukan Prioritas Calon Debitur, ANTIVIRUS, Vol. 11, No. 2, November 2017 